\title{
Contribución al estudio anatómico e histológico del ciego del cuy (Cavia porcellus) raza Perú
}

Contribution to the anatomical and histological study of the guinea pig caeca (Cavia porcellus) breed Peru.

\author{
Melissa Jara ${ }^{1}$, Roberto Valencia $(\dagger)^{1}$, Lilia Chauca ${ }^{2}$, Luis Torres ${ }^{3}$
}

\section{RESUMEN}

El objetivo del estudio fue describir la anatomía macroscópica y microscópica del ciego del cuy (Cavia porcellus). Se emplearon 26 cuyes machos de la raza Perú, distribuidos en cinco grupos etarios: 05 recién nacidos, 06 entre uno y siete días de edad, 05 de dos semanas, 05 de cuatro semanas y 05 de ocho semanas de edad. Se encontró que al nacimiento el ciego se situó en el cuadrante posterior izquierdo del abdomen completando el proceso de rotación y desarrollo a la semana de edad. A las ocho semanas, teniendo por referencia la tenia dorsal, el ciego midió $23,1 \mathrm{~cm}$ de longitud y $4,8 \mathrm{~cm}$ de diámetro externo mayor. El ciego presentó una base, un cuerpo y un vértice. Entre la primera y segunda semana de edad el ciego alcanzó su forma definitiva, y se extendió de izquierda a derecha. Externamente presentó constricciones, saculaciones y tres tenias (dorsal, ventral y craneal). Internamente presentó pliegues cecales primarios y secundarios, la papila ileal a manera de una corta proyección hacia la luz de la base del ciego y el orificio cecocólico relativamente desarrollado con una valva mayor y una menor. Las placas de Peyer se observaron a nivel de la submucosa en la curvatura mayor del ciego. Los ganglios linfáticos se localizaron externamente a nivel de la curvatura menor. Como medios de sostén el ciego presentó los pliegues: ileocecal, ileocecal accesorio y el cecocólico. El ciego presentó la túnica mucosa, submucosa, muscular y serosa. La túnica muscular estuvo compuesta por dos capas, una circular interna constante y una longitudinal externa presente sólo a nivel de las tenias.

PALABRAS CLAVE: Intestino grueso, cobayo, mucosa, placas de Peyer

\section{SUMMARY}

The present study aimed to know the anatomy and histology of the guinea pig (Cavia porcellus) cecum. Twenty six male Peru breed guinea pig were used, these were distributed in five experimental groups: five newborn, six between one and seven days old, five of two weeks, five of four weeks and five from eight weeks old. In newborn guinea pigs, the cecum was in the rear left abdominal quadrant, and the rotation process and development finished in a week. At eight weeks old, measured by the dorsal band, the cecum was $23,1 \mathrm{~cm}$ of length, and had a major external diameter of $4,8 \mathrm{~cm}$. The cecum had a base, a body and an appex. Between the first and second week of life the cecum got its definite form, and went from left to right. Externally, the cecum had constrictions, sacculations and the dorsal, ventral and cranial cecal bands. Internally, it had principal and secondary cecal folds, the papilla ilealis like a short projection to the lumen of the base of the cecum and the cecocolic hole relatively developed, with a mayor and minor valvular folds. The Peyer's patches were seen in the mayor curvature in the submucosa layer. The lymph glands appeared externally at the minor curvature. As means for supporting, the cecum had the ileocecal fold, the accessory ileocecal fold and the cecocolic fold. The cecum presented the mucosa, submucosa, muscular

\footnotetext{
Facultad de Medicina Veterinaria y Zootecnia, Universidad Peruana Cayetano Heredia. Lima, Perú.

Instituto Nacional de Innovación Agraria, Programa Nacional de Animales Menores, Proyecto Cuyes, Centro Experimental La Molina. Lima, Perú.

3 Facultad de Veterinaria, Universidad Alas Peruanas. Lima, Perú.
} 
and serosa layers. The muscular layer had two films, one constant internal circular film, and an outer longitudinal film only seen in the bands.

KEY WORDS: Large intestine, guinea pig, mucosa, Peyer's patches

\section{INTRODUCCIÓN}

El cuy o cobayo (Cavia porcellus) tiene importancia desde tiempos prehispánicos (Tineo, 2015) porque representa una fuente de proteína animal de consumo cotidiano y por su uso en la medicina tradicional (Pariona, 2014). Su crianza está difundida debido a su rápido ciclo de reproducción y requerimientos mínimos de cuidado. También por su uso como animal de laboratorio y de compañía (Newman, 2001).

En el Perú se vienen realizando diversos estudios en esta especie, entre los que destacan los de mejoramiento genético con la finalidad de mejorar su producción (Instituto Nacional de Innovación Agraria [INIA], 2018), sin embargo, los estudios de estructura anatómica y/o histológica tanto del tracto gastrointestinal como de otros órganos no son frecuentes. Padilla (2006), menciona que la microbiota existente en el ciego del cuy permite un buen aprovechamiento del alimento verde, empero con una menor eficiencia que el rumen de los rumiantes debido a que la multiplicación microbiana en el ciego en el ciego del cuy es más rápida que la acción de las enzimas proteolíticas generadas. Por ello se necesitan estudios que contribuyan a actualizar la información que se tiene en la actualidad.

En el cuy, el intestino grueso (Intestinum crassum) es un órgano sumamente desarrollado. Comprende el ciego, colon ascendente, colon transverso, colon descendente, recto y ano. En el colon ascendente destacan la ampolla y el asa espiral. El intestino grueso presenta muchas modificaciones macro y microscópicas para así descomponer las grandes cantidades de alimento rico en celulosa (Dellmann, 1993).

En el caso del cuy criollo, estudiado bajo condiciones experimentales, se demostró que la mayor, media y menor actividad fermentativa sobre el alimento se da respectivamente en el ciego, colon proximal y estómago respectivamente. Adicionalmente se encontró que la magnitud de la digestión microbiana cecal del cuy criollo, guarda cierta similitud con la encontrada en los dos primeros compartimentos estomacales de rumiantes (Esquerre, Valenzuela y Candela, 1974).
El ciego del cuy participa en la digestión de la celulosa. Es un órgano muy desarrollado, llegando a representar hasta el 15\% del peso del animal (Chauca, 1997). Presenta tenias, constricciones, saculaciones, pliegues semilunares; comunica con el íleon por medio del orificio ileal y con el colon por medio del orificio cecocólico (Valencia, 1992). Histológicamente, la característica más saltante que diferencia al intestino delgado del grueso es la ausencia de vellosidades (Church, 1993). Otras características comunes a todos los segmentos del intestino grueso son las glándulas intestinales intramurales, éstas son más rectas, largas, compactas que las del intestino delgado y poseen alta presencia de células caliciformes. Además, posee mayor número de folículos linfoides y ausencia de las células de Paneth (Dellmann, 1993).

El cuy es catalogado como un herbívoro fermentador post-gástrico. En el ciego las bacterias en su mayoría son gram negativas, sintetizan ácidos grasos volátiles, proteína microbiana y vitamina B, las que pueden ser aprovechadas por el animal mediante el proceso de cecotrofia para un buen rendimiento productivo (Chauca, 1997).

El objetivo del estudio fue describir la anatomía macroscópica y microscópica del ciego del cuy (Cavia porcellus).

\section{MATERIAL Y MÉTODOS}

Los estudios de anatomía macroscópica se realizaron en el Laboratorio de Anatomía de la Facultad de Medicina Veterinaria y Zootecnia (FAVEZ) de la Universidad Peruana Cayetano Heredia (UPCH), mientras que los de anatomía microscópica, se realizaron tanto en el Laboratorio de Histología de la FAVEZ-UPCH, como en el de la Facultad de Veterinaria de la Universidad Alas Peruanas - Sede Lurín.

Los cuyes correspondieron a las bases genéticas del Instituto Nacional de Innovación Agraria - INIA, Programa Nacional de Animales Menores - Proyecto Cuyes - Centro Experimental La Molina (CELM) Lima - Perú. Tanto los progenitores como la progenie fueron criados bajo un mismo sistema de manejo de 
producción intensiva y alimentación mixta. Los cuyes usados en el estudio se obtuvieron del galpón $1 \mathrm{y}$ correspondieron a la generación IVL.

En el estudio se emplearon 26 cuyes machos raza Perú agrupados en cinco grupos etarios divididos en: Recién nacidos $(\mathrm{n}=5)$, entre uno y siete días de edad $(\mathrm{n}=6)$, dos semanas de edad $(\mathrm{n}=5)$, cuatro semanas de edad $(n=5)$ y ocho semanas de edad $(n=5)$.

La eutanasia se practicó con sobredosis de pentobarbital sódico, $120 \mathrm{mg} / \mathrm{kg}$ de peso vivo, vía intraperitoneal, correspondiente al menos al triple de la dosis anestésica (dosis de anestesia general $30-40 \mathrm{mg} / \mathrm{kg}$ peso vivo (Carpenter, 2001), según recomendaciones de la Asociación Médico Veterinaria Americana (AVMA, 2013).

El estudio macroscópico del ciego comprendió su relación con la topografía corporal, la posición y relaciones in situ. Se registró el peso con y sin contenido alimenticio utilizando una balanza digital en gramos ( $\left.{ }^{\circledR} S O E H N L E\right)$. Para la medida de longitud se consideró la tenia dorsal por ser de fácil identificación y experimentar menor variación con su repleción. La curvatura menor se consideró como la distancia comprendida entre la llegada del íleon y el inicio del colon. Se describieron la superficie externa e interna del ciego, su sistema linfoide y sus relaciones con el íleon y colon. Para las mediciones de longitud se utilizó una regla en milímetros.
En la observación de estructuras del grupo de recién nacidos se utilizó un microscopio estereoscópico (Carl Zeiss - Steamy DV4).

Para el estudio histológico, se tomaron muestras de los grupos recién nacidos y ocho semanas de edad. Se utilizó la tinción Hematoxilina - Eosina y la tinción Tricrómico de Mallory para detalles en las capas musculares. La observación de las láminas se realizó mediante el uso de un microscopio ocular Carl Zeiss - Axiostar Plus y un microscopio ocular LEICA DM 750, ICC 50 HD, Software LAS.

Los resultados cuantitativos son resumidos mediante cuadros de frecuencia, tomando como medida de tendencia central a la media aritmética. La relación de las de longitud entre los tres segmentos del ciego del cuy se presenta en gráficos de barras. En fotografías se describen las características de los ciegos estudiados.

\section{RESULTADOS}

El ciego del cuy se dividió en una base, un cuerpo y un vértice, siendo el cuerpo la porción con mayor desarrollo, seguido del vértice y la base (figura $1 \mathrm{y}$ gráfico1).

La rotación del ciego hacia su posición final ocurrió dentro de la primera semana de vida. En cinco cuyes recién nacidos el ciego se relacionó al
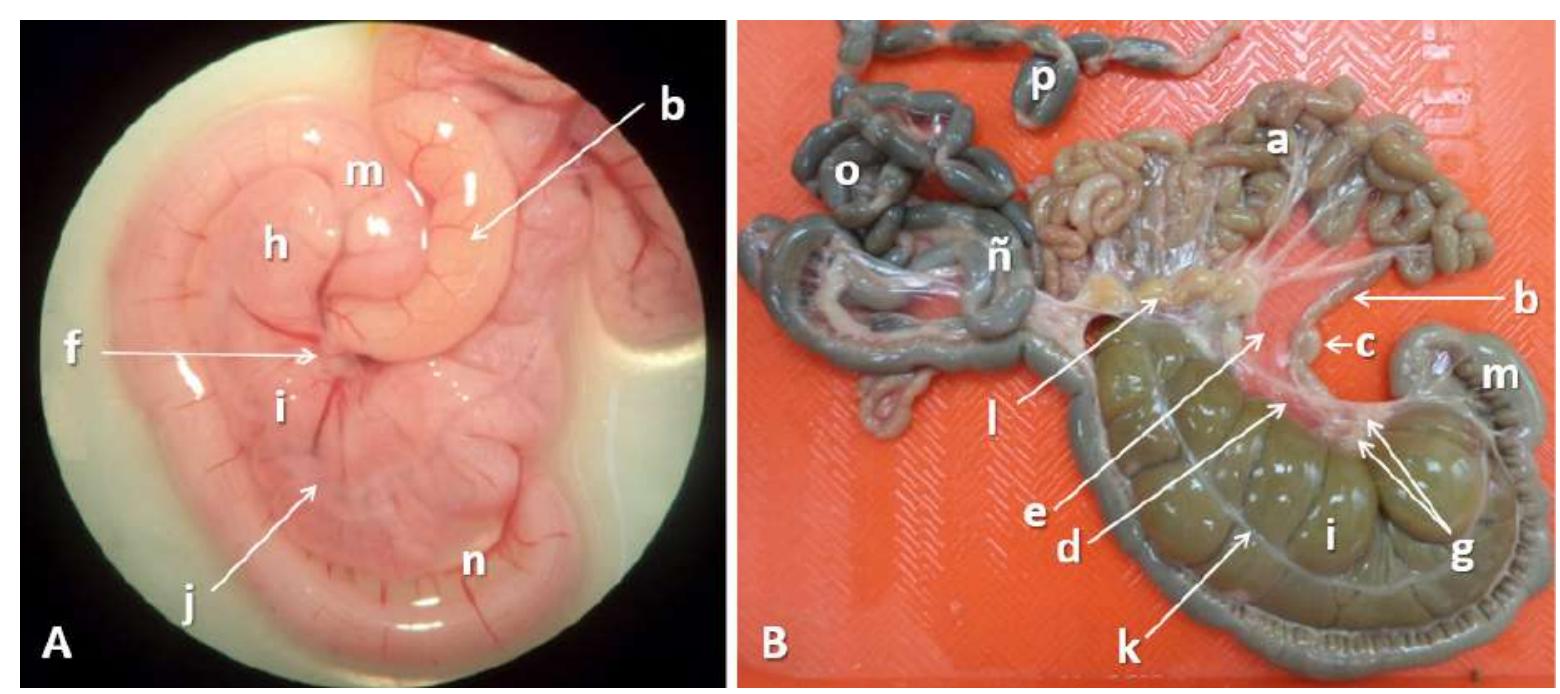

a. Yeyuno, b. Íleon, c. Placa de Peyer del íleon, d. Pliegue ileocecal, e. Mesoíleon, f. Ganglios linfáticos cecales, g. Ganglios linfáticos ileocecales, h. Base del ciego, i. Cuerpo del ciego, j. Tenia dorsal, k. Tenia ventral, 1. Ganglios linfáticos mesentéricos craneales, m. Colon ascendente, n. Pliegue cecocólico, ñ. Asa espiral del colon ascendente, o. Colon transverso, p. Colon descendente.

Figura 1. Vista ventral del ciego del cuy (Cavia porcellus) masculino raza Perú. A: Recién nacido (8x), B: Ocho semanas de edad presentando los intestinos extendidos. 


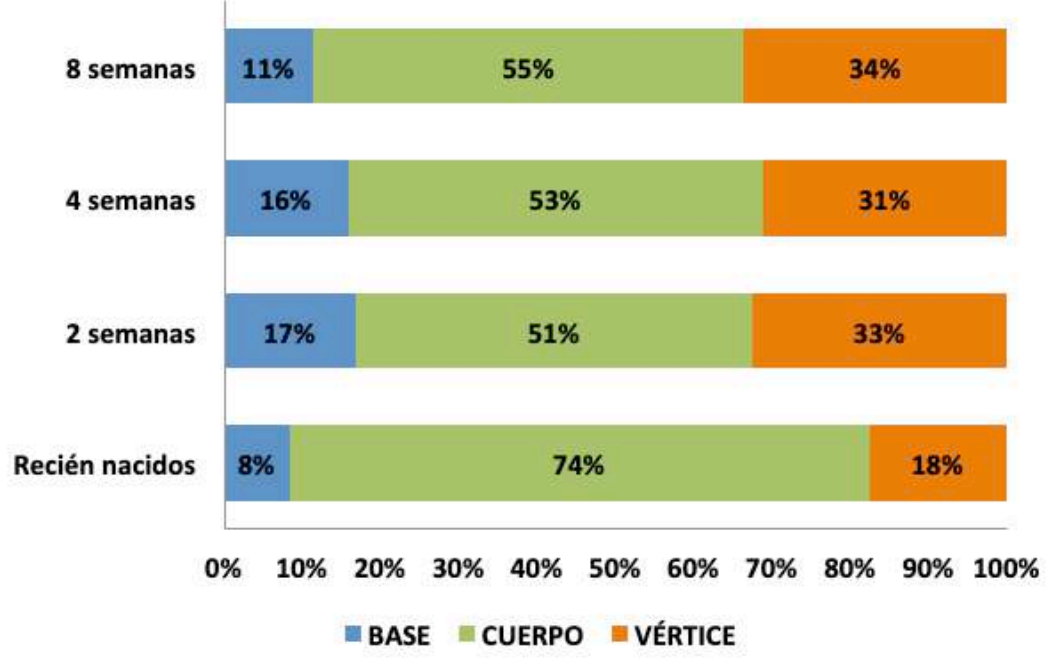

Gráfico 1. Relación de longitud entre los tres segmentos del ciego del cuy (Cavia porcellus) masculino, Raza Perú
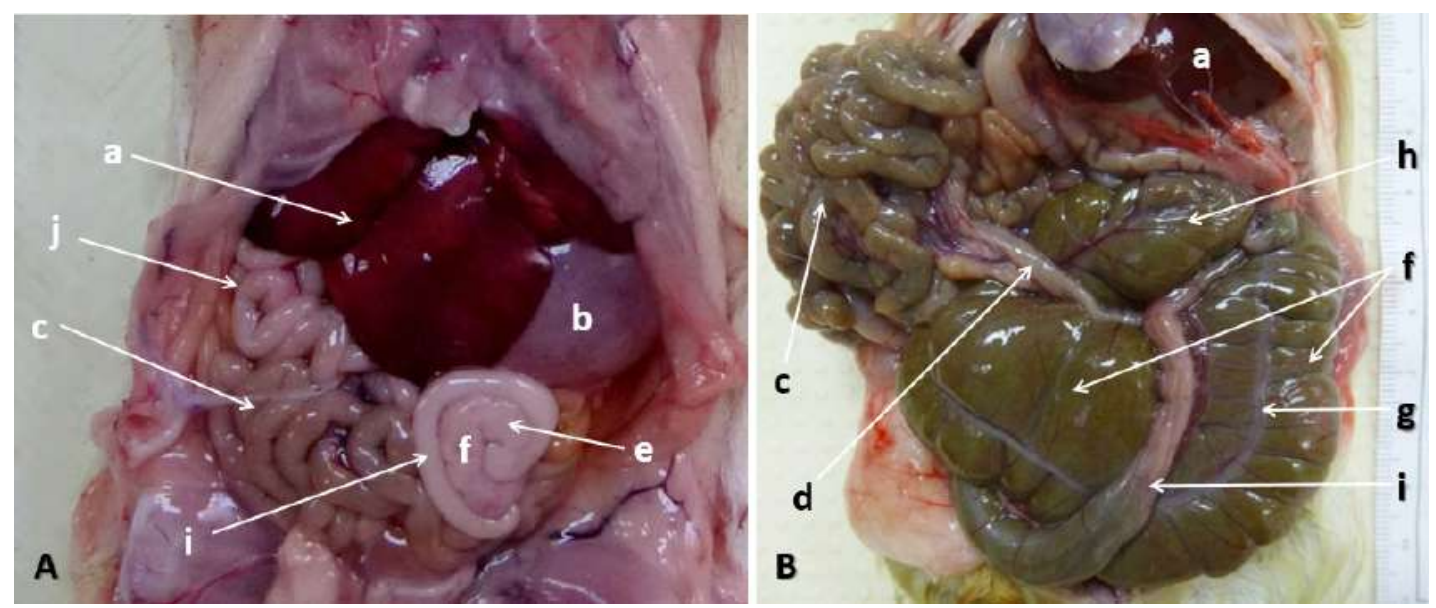

a. Hígado, b. Estómago, c. Yeyuno, d. Íleon, e. Base del ciego, f. Cuerpo del ciego, g. Tenia ventral, h. Vértice del ciego, i. Colon ascendente, j. Colon transverso.

Figura 2. Vista ventral del ciego en el cuy (Cavia porcellus) masculino raza Perú.

A: Recién nacido, B: Dos semanas de edad (se han desplazado las asas del yeyuno e íleon).

cuadrante posterior izquierdo del abdomen, mientras que la base y porción proximal del cuerpo del ciego se encontraron en posición ventral en dirección cráneo caudal de derecha a izquierda (figura 2).

El proceso de rotación finalizó situando la base del ciego en posición dorsal izquierda, el cuerpo adoptó la forma de una "V" en ventral seguida del vértice del ciego en posición transversal (figura 3).

En cuatro especímenes de dos semanas de edad, el ciego se ubicó en posición ventral y ocupó la mayor parte de la cavidad abdominal (figura 2). Limitó en craneal con el hígado, en caudal y a la derecha con asas del yeyuno, íleon y colon ascendente; y a la izquierda con el inicio del colon ascendente y pared abdominal. Los especímenes de cuatro y ocho semanas de edad conservaron la forma y disposición final observada en el ciego de cuyes de dos semanas de edad.

La longitud total del ciego y de sus porciones medidas por la tenia dorsal se observan en la tabla 1 .

En las edades estudiadas, la base del ciego se observó de forma redondeada, presentando constricciones principales y secundarias además de 


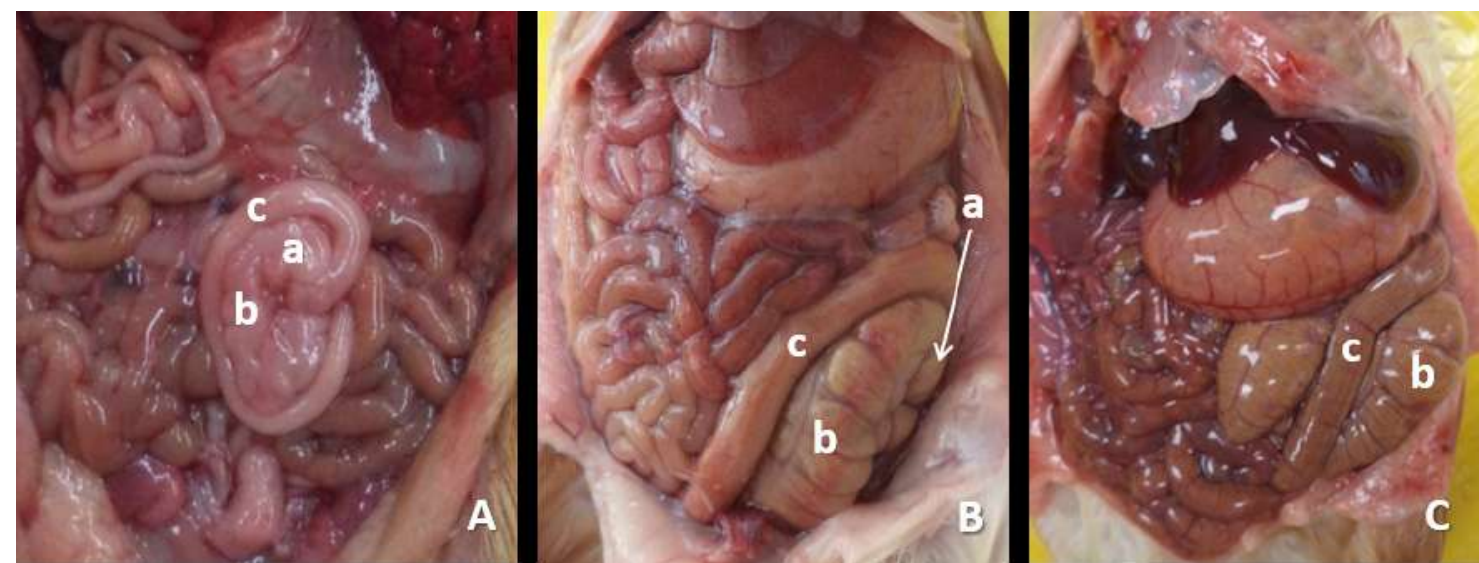

a. Base del ciego del cuy, b. Porción descendente del cuerpo del ciego del cuy, c. Colon ascendente.

Figura 3. Vistas ventrales que ilustran la rotación del ciego del cuy (Cavia porcellus) masculino raza Perú. A: Cuy recién nacido, B: Cuy de 1 día de edad, C: Cuy de 2 días de edad.

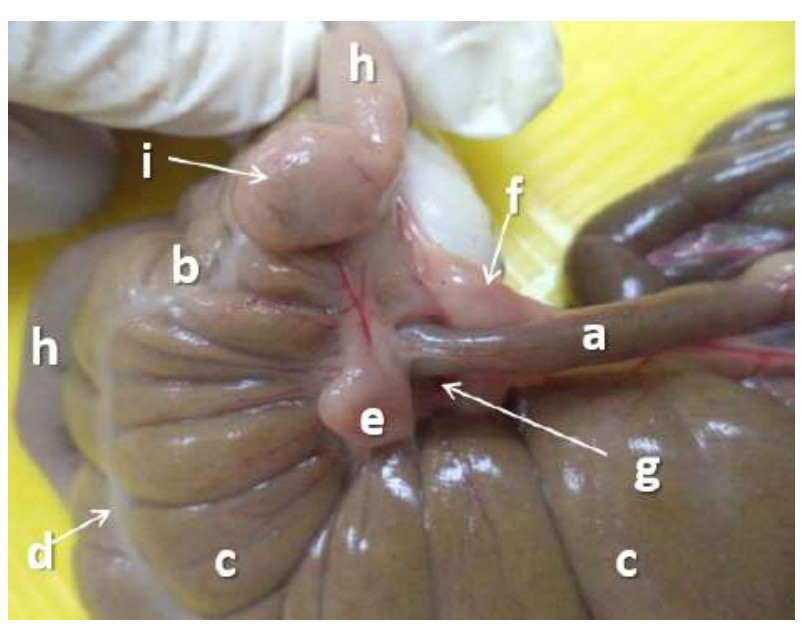

a. Íleon, b. Base del ciego, c. Cuerpo del ciego, d. Tenia dorsal, e. Ganglio linfático cecal, f. Ganglio linfático ileocecal, g. Espacio del pliegue ileocecal, h. Colon ascendente, i. Placa de Peyer de la ampolla del colon ascendente.

Figura 4. Vista dorsal de la base del ciego del cuy (Cavia porcellus) masculino de ocho semanas de edad raza Perú.

saculaciones. La curvatura menor de la base del ciego fue de trayecto corto, se extendió de la llegada del íleon a la constricción cecocólica (figura 4). Completada la rotación, la curvatura menor se localizó en dorsal y al lado izquierdo del abdomen. Internamente la base del ciego presentó la papila ileal y el orificio cecocólico (figura 5).

La papila ileal se observó a manera de una evaginación cilíndrica de color claro del íleon hacia la luz del ciego. Presentó bordes gruesos con el orificio ileal cerrado. En el recién nacido la papila ileal midió en promedio $1,5 \mathrm{~mm}$ de alto y $2,2 \mathrm{~mm}$ de diámetro externo. En el cuy de 8 semanas de edad midió 2,1 $\mathrm{mm}$ de alto y $3,2 \mathrm{~mm}$ de diámetro externo en promedio (tabla 2).

El orificio cecocólico del recién nacido midió en promedio $1 \mathrm{~mm}$ de diámetro interno; en los cuyes de 8 semanas de edad midió $6 \mathrm{~mm}$ en promedio. Presentó dos valvas, una mayor muy desarrollada (promedio $3 \times 1,8 \mathrm{~mm}$ en el recién nacido y $12,5 \times 8,3 \mathrm{~mm}$ en promedio a las 8 semanas) que obliteró completamente el orificio cecocólico, y otra menor (promedio 2,2 x $1,5 \mathrm{~mm}$ en el recién nacido y 9 x $5,5 \mathrm{~mm}$ en promedio a las 8 semanas) (tabla 2). Ambas valvas fueron de paredes y bordes libres, delgados y lisos. La valva mayor se ubicó en dorsal, relacionada externamente al borde mesentérico del colon ascendente y la valva menor en ventral, relacionada externamente al borde libre del colon ascendente. La papila ileal y el orificio cecocólico se dispusieron en un mismo eje. En cuyes de ocho semanas de edad la distancia entre ambas estructuras fue de aproximadamente $6 \mathrm{~mm}$.

Completada su rotación, el cuerpo del ciego se dispuso en forma de una "V". Presentó una porción descendente (proximal) y una porción ascendente (distal) divididas por una flexura (caudal), siendo más desarrollada la porción distal. Externamente presentó constricciones, saculaciones y tenias. Internamente las constricciones se correspondieron con pliegues cecales (figura 5).

El vértice del ciego se observó desarrollado, delimitado del cuerpo por una profunda flexura craneal. Se relacionó con el íleon por medio del pliegue ileocecal accesorio que lo acompañó hasta el punto medio de su trayecto, el extremo distal del vértice fue libre, lo cual le permitió variar de posición (gráfico 2). 
Tabla 1. Promedio de medidas del ciego $(\mathrm{cm})$ con contenido en cuyes (Cavia porcellus) masculinos raza Perú en cuatro edades.

\begin{tabular}{|c|c|c|c|c|c|c|c|}
\hline Edad & Base $^{1}$ & Cuerpo $^{1}$ & Vértice $^{1}$ & $\begin{array}{l}\text { Long. } \\
\text { Ciego }^{1}\end{array}$ & $\begin{array}{c}\text { Curvatura } \\
\text { Mayor }^{2}\end{array}$ & $\begin{array}{c}\text { Curvatura } \\
\text { Menor }^{3}\end{array}$ & $\begin{array}{c}\text { Diámetro } \\
\text { ciego }^{4}\end{array}$ \\
\hline Recién nacidos & 0,5 & 4,2 & 1,0 & 5,7 & 8,9 & 1,0 & 5,1 \\
\hline 2 semanas & 2,5 & 7,4 & 4,7 & 14,6 & 24,2 & 1,8 & 2,8 \\
\hline 4 semanas & 3,2 & 10,6 & 6,2 & 20,0 & 29,1 & 2,6 & 3,6 \\
\hline 8 semanas & 2,7 & 12,7 & 7,8 & 23,2 & 38,7 & 6,0 & 4,8 \\
\hline
\end{tabular}

${ }^{1}$ Longitud medida por la tenia dorsal.

${ }^{2}$ Longitud de la Curvatura mayor del ciego tomada entre la llegada del íleon e inicio del colon por el borde externo convexo y cóncavo del ciego.

${ }^{3}$ Longitud de la Curvatura menor del ciego tomada entre la llegada del íleon y el inicio del colon, medido por el borde interno, cóncavo.

${ }^{4}$ Diámetro del ciego medido en el punto medio de su recorrido.
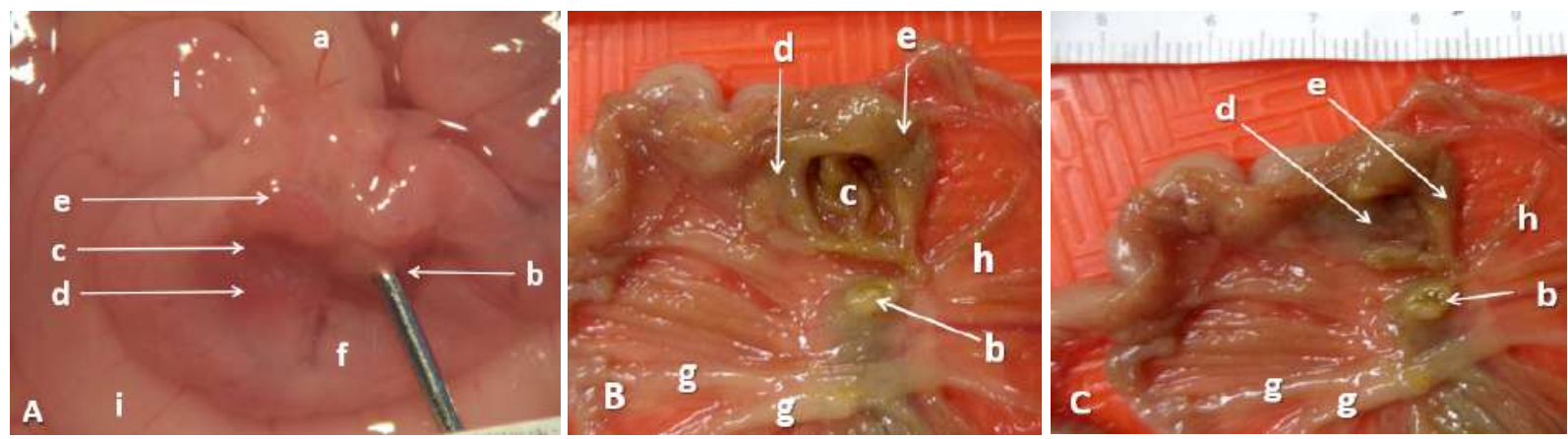

a. Íleon, b. Papila ileal, c. Orificio cecocólico, d. Valva mayor, e. Valva menor, f. Mucosa del ciego, g. Pliegues primarios, h. Pliegues secundarios, i. Colon ascendente.

Figura 5. Vista de la cara interna de la base del ciego en el cuy (Cavia porcellus) masculino raza Perú. A: Recién nacido (8x), B: Cuatro semanas con el orificio cecocólico descubierto, C: Cuatro semanas con el orificio cecocólico cubierto.

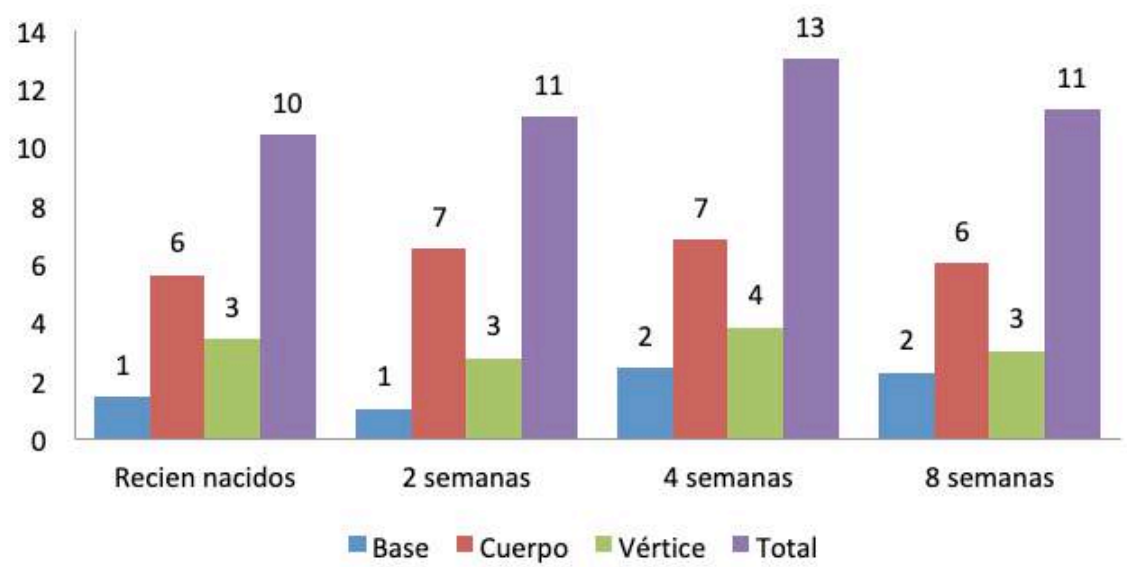

Gráfico 2. Promedio del número de saculaciones por fila a nivel de la curvatura mayor del ciego de cuyes (Cavia porcellus) machos raza Perú

Los animales recién nacidos presentaron el vértice en posición dorsal, en dos de ellos dirigidos de izquierda a derecha y en tres especímenes dirigidos de derecha a izquierda. De quince especímenes, entre dos a ocho semanas de edad, se observó que en seis de ellos el vértice se dirigió de izquierda a derecha generalmente en sentido ventral, mientras que en siete animales se dirigió de derecha a izquierda, todos en sentido dorsal (figura 2). El número de saculaciones del vértice en comparación al cuerpo fue en relación de 1:2 (gráfico 2). 

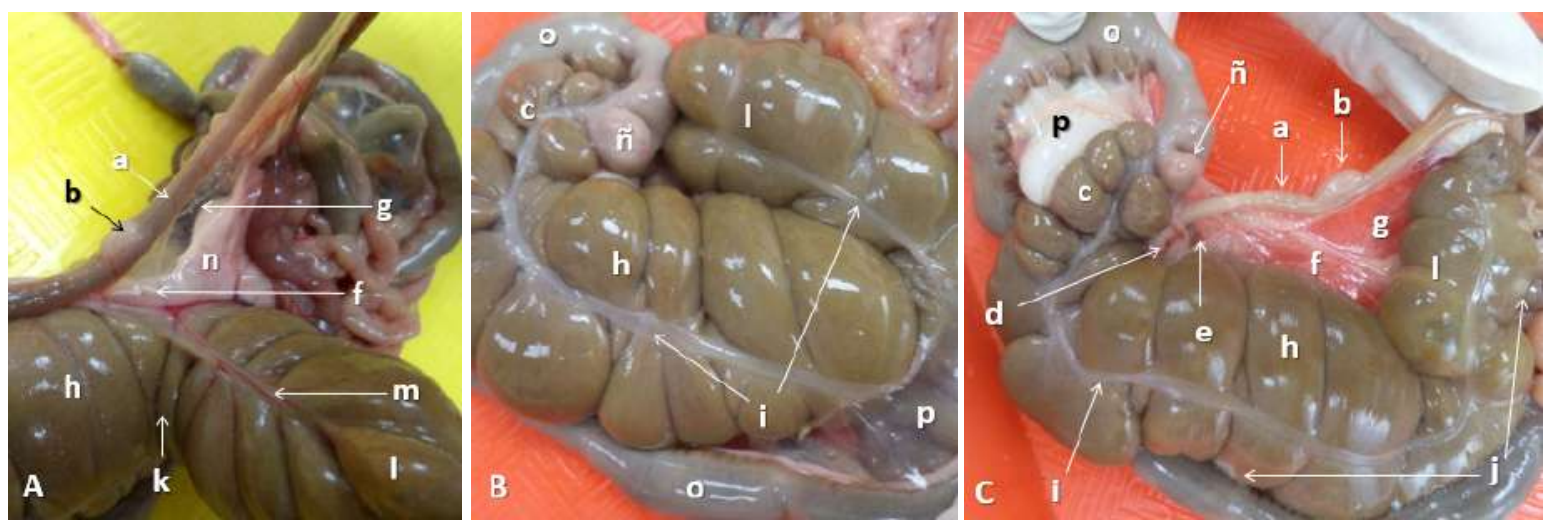

a. Íleon, b. Placa de Peyer del íleon, c. Base del ciego, d. Ganglio linfático cecal, e. Abertura del pliegue ileocecal, f. Pliegue ileocecal accesorio, g. Mesoíleon, h. Cuerpo del ciego, i. Tenia dorsal, j. Placas de Peyer del ciego, k. Constricción que separa cuerpo y vértice del ciego, 1. Vértice del ciego, m. Tenia craneal (mesentérica), n. Ganglios linfáticos mesentéricos craneales, ñ. Placa de Peyer de la ampolla del colon ascendente, o. Colon ascendente, p. Pliegue cecocólico.

Figura 6. Vista dorsal de los pliegues ileocecal accesorio y cecocólico en el cuy (Cavia porcellus) masculino raza Perú. A: Ocho semanas, B: Cuatro semanas, C: Cuatro semanas

Tabla 2. Promedio de medidas $(\mathrm{mm})$ de la papila ileal, orificio y valvas cecocólicas en cuyes (Cavia porcellus) masculinos raza Perú en cuatro edades.

\begin{tabular}{cccccccc}
\hline & \multicolumn{3}{c}{ Papila ileal } & \multicolumn{5}{c}{ Orificio cecocólico } \\
\hline Edad & $\begin{array}{c}\text { Altura } \\
\text { papila }\end{array}$ & $\begin{array}{c}\text { Diámetro externo } \\
\text { papila }\end{array}$ & $\begin{array}{c}\text { Diámetro } \\
\text { interno orificio } \\
\text { cecocólico }\end{array}$ & \multicolumn{4}{c}{ Valva mayor } \\
Largo & Ancho & Largo & Ancho \\
\hline Recién nacidos & 1,5 & 2,2 & 1 & 3 & 1,8 & 2,5 & 1,5 \\
2 semanas & 2,5 & 2,6 & 4,3 & 8 & 4,6 & 3,8 & 2,3 \\
4 semanas & 2,4 & 3,1 & 5,2 & 10,4 & 5,1 & 4,2 & 2,4 \\
8 semanas & 2,1 & 3,2 & 6 & 12,5 & 8,3 & 9 & 5,5 \\
\hline
\end{tabular}

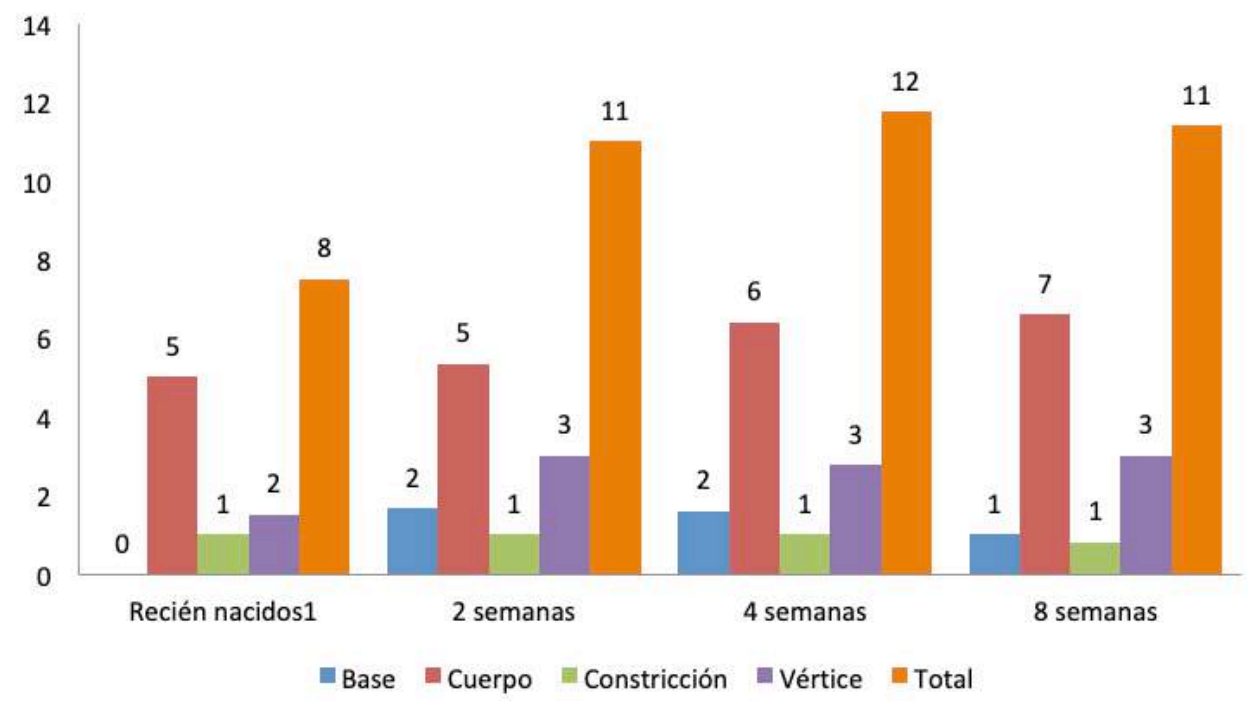

${ }^{1}$ Observables solo en embalsamados.

Grafico 3. Número de placas de Peyer en el ciego del cuy (Cavia porcellus) macho raza Perú. 
Las paredes del ciego estuvieron surcadas longitudinalmente por tres tenias o cintas: dorsal, ventral y craneal (mesentérica), macroscópicamente se observan como haces de color claro de músculo liso. Las tenias dorsal y ventral se extendieron desde la base del ciego hasta el ápice del vértice del ciego, mientras que la tenia craneal llegó hasta la última constricción del vértice. La rotación y desarrollo del ciego influyeron en el trayecto de las tenias, excepto en la tenia craneal (figura 1). Completada la rotación, la tenia ventral empezó en la base del ciego avanzando libre por un corto trayecto para luego unirse al pliegue cecocólico desde el término de la base hasta la flexura caudal del cuerpo, a partir de la cual recorrió libre la superficie ventral del cuerpo hasta el vértice del ciego. La tenia dorsal se observó libre a nivel de la base y cuerpo del ciego, para luego unirse al pliegue cecocólico poco antes de la flexura caudal del cuerpo y continuar unida hasta la flexura craneal entre el cuerpo y vértice, terminando finalmente en la superficie dorsal del vértice del ciego (Figura 6). La tenia craneal (mesentérica) conservó su relación con el pliegue ileocecal y posición a lo largo del borde cóncavo del ciego (figura 6). Se encontró diferencia en el ancho de las tenias, a favor de la tenia dorsal.

El ciego del cuy presentó saculaciones transversales de variado desarrollo delimitadas longitudinalmente por tenias. El promedio de saculaciones en cuyes recién nacidos y en cuyes de ocho semanas de edad fue de diez y once respectivamente (grafico 2). Los pliegues correspondieron internamente a las constricciones externas. Las constricciones más profundas y espaciadas formaron pliegues primarios, desarrollados y constantes. También se observaron constricciones menos profundas e inconstantes formando pliegues secundarios (figura 5).

El íleon se unió al ciego por medio de 2 pliegues, el pliegue ileocecal que inició en la base del ciego, y el pliegue ileocecal accesorio, de forma triangular y continuación del pliegue ileocecal hasta el punto medio del vértice del ciego (figura 1 y figura 6). A nivel de la llegada del íleon al ciego, relacionado al pliegue ileocecal, se observó un área libre de pliegues, donde se localizaron los ganglios linfáticos ileocecales en ventral y el ganglio linfático cecal en dorsal (figura 4 y figura 6). En los especímenes de ocho semanas de edad, el promedio del diámetro externo del íleon a su llegada al ciego fue de $4,5 \mathrm{~mm}$.

El colon ascendente se reconoció por la constricción que lo separó del ciego (figura 2). En el animal recién nacido el colon acompañó al ciego, por su curvatura mayor, de la base al inicio del vértice por medio del pliegue cecocólico. A partir de las dos semanas de edad, el colon inició en la superficie dorsal de la base del ciego unido por medio del pliegue cecocólico (figura 6), el pliegue se unió inmediatamente a la tenia ventral y recorrieron juntos hasta la flexura caudal del cuerpo. De allí cruzaron sobre el cuerpo para unirse a la tenia dorsal y recorrer la porción ascendente del cuerpo, finalmente se separó del ciego a nivel de la flexura craneal entre el cuerpo y vértice (figura 6). El promedio del diámetro externo del inicio del colon ascendente fue de $11,3 \mathrm{~mm}$.

Tanto el íleon como el colon presentaron placas de Peyer en la cercanía al ciego. En el íleon a pocos centímetros de la llegada al ciego, se observó en el

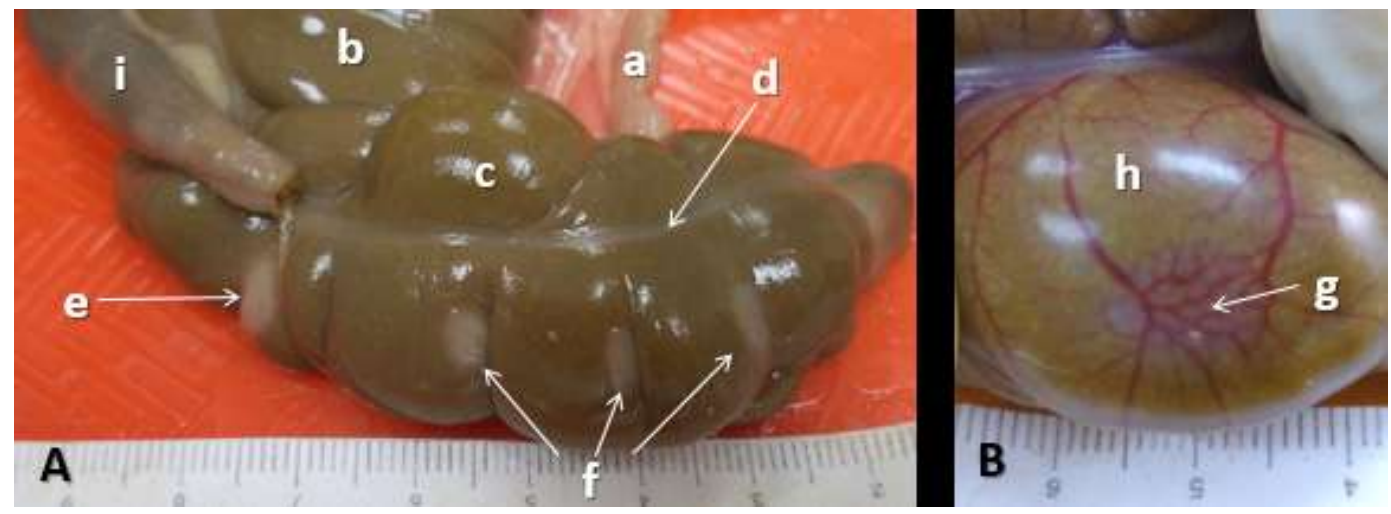

a. Íleon, b. Cuerpo del ciego, c. Vértice del ciego, d. Tenia dorsal, e. Placa de Peyer en la constricción entre el cuerpo y el vértice, f. Placas de Peyer del vértice, g. Placa de Peyer, h. Pared del ciego, i. Colon ascendente.

Figura 7. Ciego del cuy (Cavia porcellus) masculino raza Perú. A: Vista dorsal del vértice del ciego del cuy de ocho semanas, B: Vista de una placa de Peyer en la pared externa del ciego del cuy de cuatro semanas de edad. 


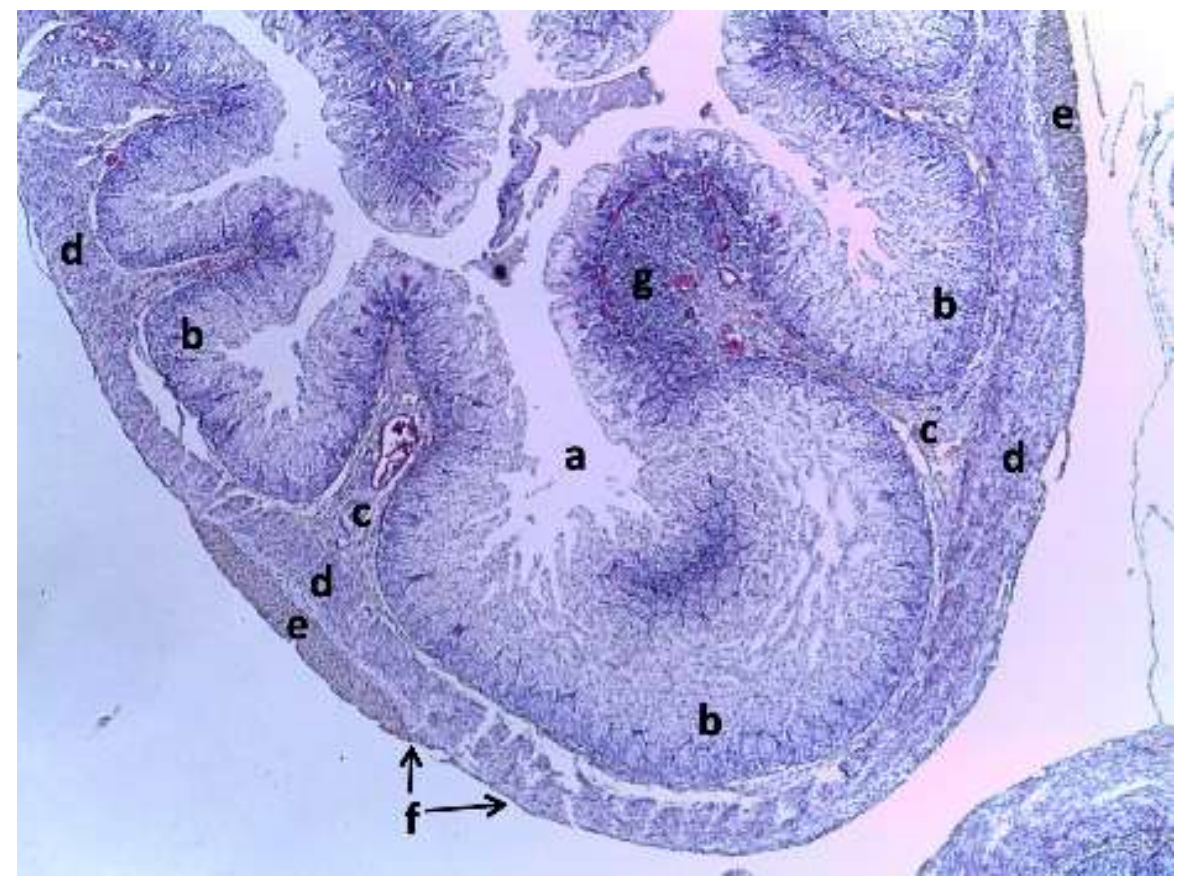

a. Luz del ciego, b. Túnica mucosa, c. Túnica submucosa, d. Túnica muscular capa circular interna, e. Túnica muscular capa longitudinal externa (tenia), f. Túnica serosa, g. Folículo linfoide.

Figura 8. Base del ciego del cuy (Cavia porcellus) masculino recién nacido raza Perú (4x). Tinción H-E.
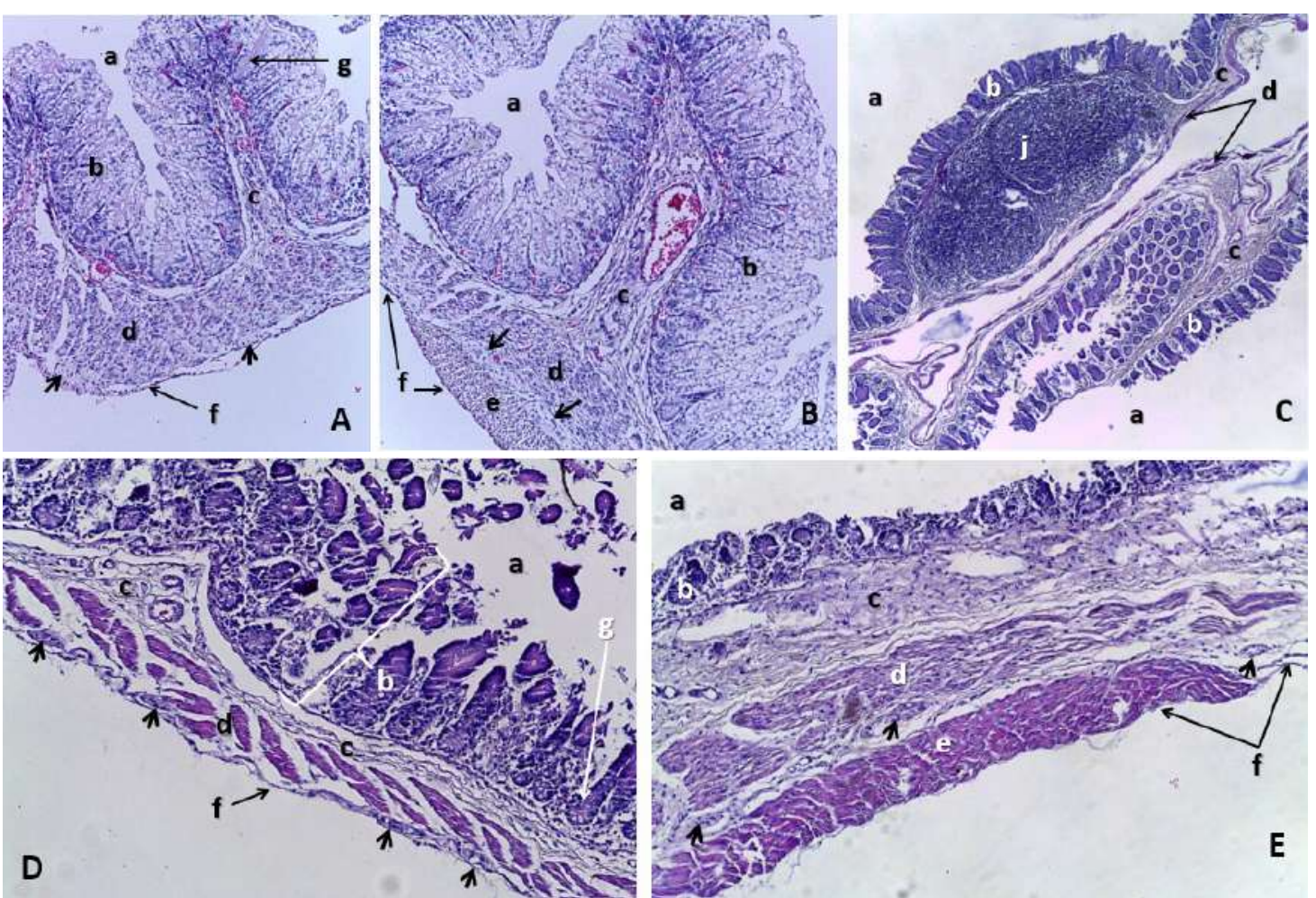

a. Luz del ciego, b. Túnica mucosa, c. Túnica submucosa, d. Túnica muscular capa circular interna, e. Túnica muscular longitudinal externa (tenia), f. Túnica serosa, g. Glándulas de Lieberkühn, j. Placas de Peyer. Flechas señalan plexos nerviosos.

Figura 9. Pared del ciego del cuy (Cavia porcellus) masculino raza Perú, tinción H-E.

A, B: Recién nacido (10x), C, D, E: Ocho semanas (10x). 
Tabla 3. Promedio de medidas ( $\mathrm{mm})$ de los ganglios linfáticos (NL) relacionados al ciego en cuyes (Cavia porcellus) masculinos raza Perú en cuatro edades.

\begin{tabular}{ccccccc}
\hline \multirow{2}{*}{ Edad } & \multicolumn{2}{c}{ NL Cecal } & \multicolumn{2}{c}{ NL Ileocecales } & \multicolumn{2}{c}{ NL Mesentérico } \\
\cline { 2 - 7 } & Largo & Ancho & Largo & Ancho & Largo & Ancho \\
\hline Recién nacidos & 1,6 & 1 & 1,9 & 1,2 & 3 & 1,7 \\
2 semanas & 4 & 3,1 & 4,8 & 1,9 & 8,4 & 5,3 \\
4 semanas & 6,4 & 4,9 & 5,9 & 3,2 & 8,3 & 4,7 \\
8 semanas & 9,5 & 8 & 7,2 & 3,9 & 12,1 & 6,9 \\
\hline
\end{tabular}

Tabla 4. Promedio de medidas ( $\mathrm{mm}$ ) de placas de Peyer en el ciego de cuyes (Cavia porcellus) masculinos raza Perú en cuatro edades.

\begin{tabular}{cccccccccc}
\hline \multirow{2}{*}{ Edad } & \multicolumn{8}{c}{ Partes del ciego } \\
\cline { 2 - 10 } & \multicolumn{2}{c}{ Cabeza } & \multicolumn{2}{c}{ Cuerpo } & \multicolumn{2}{c}{ Flexura $^{1}$} & \multicolumn{2}{c}{ Cola } \\
& \multicolumn{2}{c}{ Largo } & Ancho & Largo & Ancho & Largo & Ancho & Largo & Ancho \\
\hline \multirow{2}{*}{ Recién nacidos $^{2}$} & \multicolumn{2}{c}{ No visibles } \\
& macroscópicamente & 1,3 & 1 & 2 & 1 & 0,8 & 0,8 \\
2 semanas & 2,8 & 3,0 & 2,9 & 3,2 & 2 & 5 & 2,3 & 3,7 \\
4 semanas & 2,9 & 2,4 & 4,1 & 3,5 & 5 & 3,8 & 3,3 & 2,9 \\
8 semanas & 3,8 & 3,5 & 6,3 & 5,1 & 6,9 & 4,8 & 5,5 & 3,9 \\
\hline
\end{tabular}

${ }^{1}$ Flexura que separa el cuerpo del vértice del ciego

${ }^{2}$ Sólo observables en embalsamados.

Tabla 5. Relación entre el promedio de peso vivo y el promedio de peso (g) del ciego con contenido en cuyes (Cavia porcellus) masculinos raza Perú en cuatro edades.

\begin{tabular}{cccc}
\hline Edad & Peso vivo & Peso ciego con contenido & Relación PV $^{1}$ y PCCC $^{2}$ \\
\hline Recién nacidos & 138,2 & $<1$ & $1 \%$ \\
2 semanas & 195,8 & 19 & $10 \%$ \\
4 semanas & 272,2 & 32,3 & $12 \%$ \\
8 semanas & 854,7 & 68,3 & $8 \%$ \\
\hline
\end{tabular}

${ }^{1} \mathrm{PV}$ : Peso vivo

${ }^{2}$ PCCC: Peso del ciego del cuy con contenido

borde libre una elevación ovalada correspondiente a una placa de Peyer (figura 1 y figura 6). El colon ascendente en su inicio presentó una ampolla de superficie ovalada de color claro correspondiente también a una placa de Peyer (figura 4 y figura 6). El pliegue ileocecal unió el íleon al ciego por medio de la tenia craneal desde el límite entre la base y el cuerpo hasta la altura de la placa de Peyer del íleon.

El ciego de los cuyes recién nacidos presentó placas de Peyer, pequeñas y en número variable (tabla 4). Se encontraron mayormente en la submucosa de la curvatura mayor del ciego, algunas ocultas macroscópicamente por las constricciones. Se observaron de forma ovalada, de color rosado a manera de panal de abejas muchas veces acompañadas de una trama de vasos sanguíneos dispuestos en forma de red. A nivel de la flexura craneal entre el cuerpo y vértice fue constante la presencia de una placa de Peyer (grafico 3 y figura 7). En los recién nacidos fueron observadas posterior a la fijación del órgano.

Los ganglios linfáticos mesentéricos fueron de forma ovalada, tamaño variado, superficie lisa y color rosado (tabla 3). Relacionado a la superficie dorsal de la base del ciego, próximo a la llegada del íleon e inicio del colon, se observó al pequeño ganglio linfático cecal, generalmente único, de forma ovalada y color rosado (figura 1 y figura 4). Situados en posición ventral, se observaron los ganglios linfáticos ileocecales relativamente pequeños, ubicados sobre el pliegue ileocecal a la altura de la división de base y cuerpo (figura 1 y figura 4). Finalmente, en ventral, sobre la flexura que divide cuerpo y vértice se ubicó 


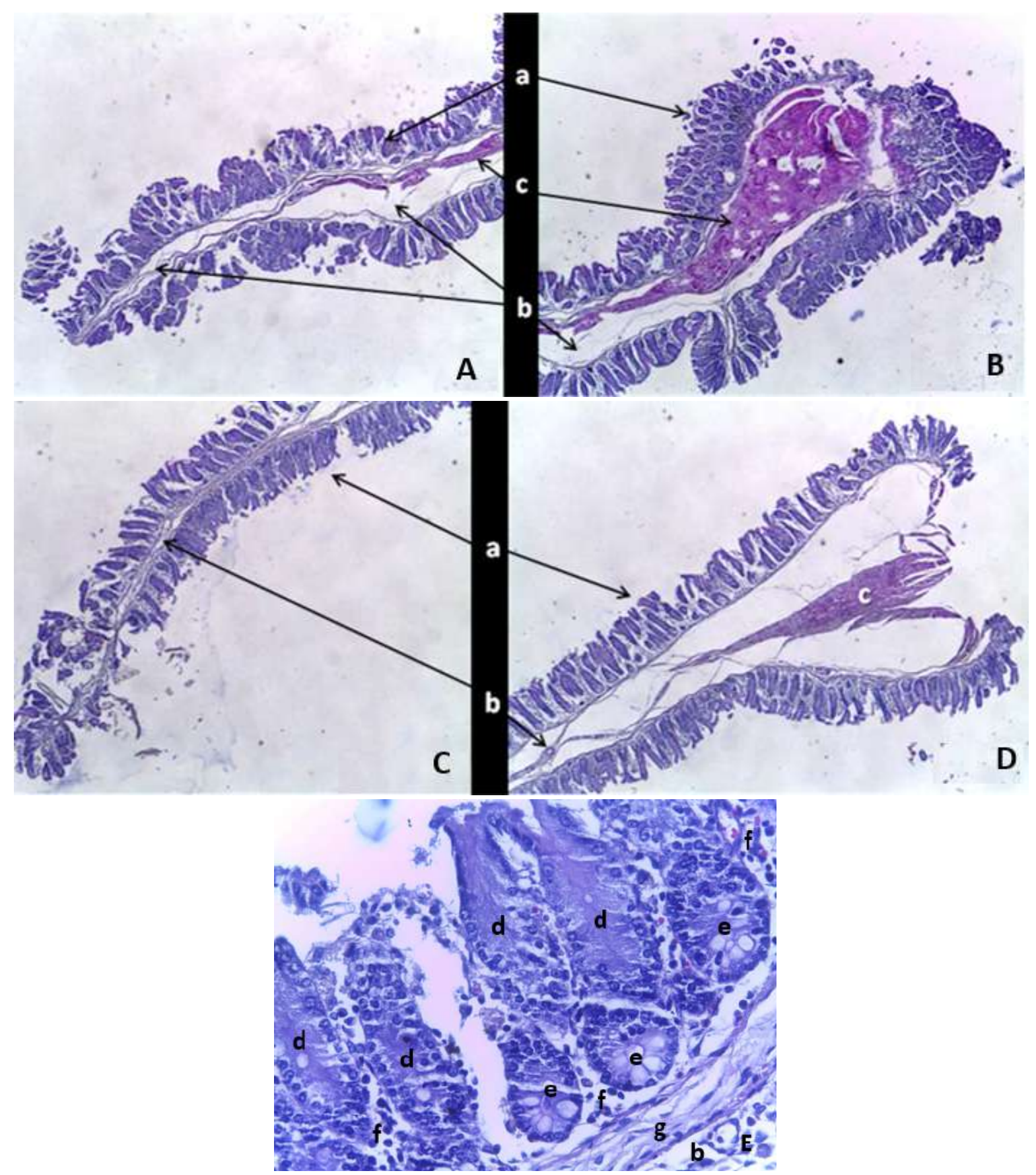

a. Túnica mucosa, b. Túnica submucosa, c. Porción muscular, d. Criptas de Lieberkühn, e. Glándulas de Lieberkühn, f. Lámina propia, g. Muscular de la mucosa.

Figura 10. Válvula cecocólica del ciego del cuy (Cavia porcellus) masculino de 8 semanas raza Perú, tinción H-E. A: Vértice de la valva mayor (4x), B: Base de la valva mayor (4x), C: Vértice de la valva menor, D: Base de la valva menor, E: Túnica mucosa de la valva mayor (40x).

el ganglio linfático mesentérico craneal conformado por un ganglio linfático de mayor tamaño y otros medianos (figura 1).

El estudio histológico del ciego del cuy recién nacido muestra que las estructuras son similares a las de los grupos de mayor edad (figura 8 y figura 9).
La túnica mucosa del ciego presentó un epitelio simple cilíndrico, con presencia de células caliciformes. La túnica mucosa se invaginó formando criptas llamadas glándulas de Lieberkühn, así mismo se observó una fina muscular de la mucosa. En la lámina propia se observaron abundantes células plasmáticas y escasos linfocitos. 
La túnica submucosa presentó abundante tejido conjuntivo laxo con presencia de vasos sanguíneos, vasos linfáticos y plexos nerviosos submucosos o plexos de Meissner. La capa circular interna de la túnica muscular se observó por secciones desorganizada, con presencia de tejido conjuntivo laxo (figura 9). La capa longitudinal externa de la túnica muscular, se observó sólo a nivel de las tenias musculares del ciego, mostrando apariencia compacta (figura 9). Además, se observaron plexos nerviosos mientéricos o plexos de Auerbach entre ambas capas musculares lisas en el estrato intermuscular de tejido conectivo. La túnica serosa estuvo constituida por la presencia de epitelio simple plano y tejido conjuntivo laxo, donde se localizaron algunos plexos nerviosos subserosos, excepto a nivel de las tenias. Las placas de Peyer se observaron como múltiples agregaciones de folículos linfoides ubicadas entre la capa muscular de la mucosa y la capa submucosa (figura 9).

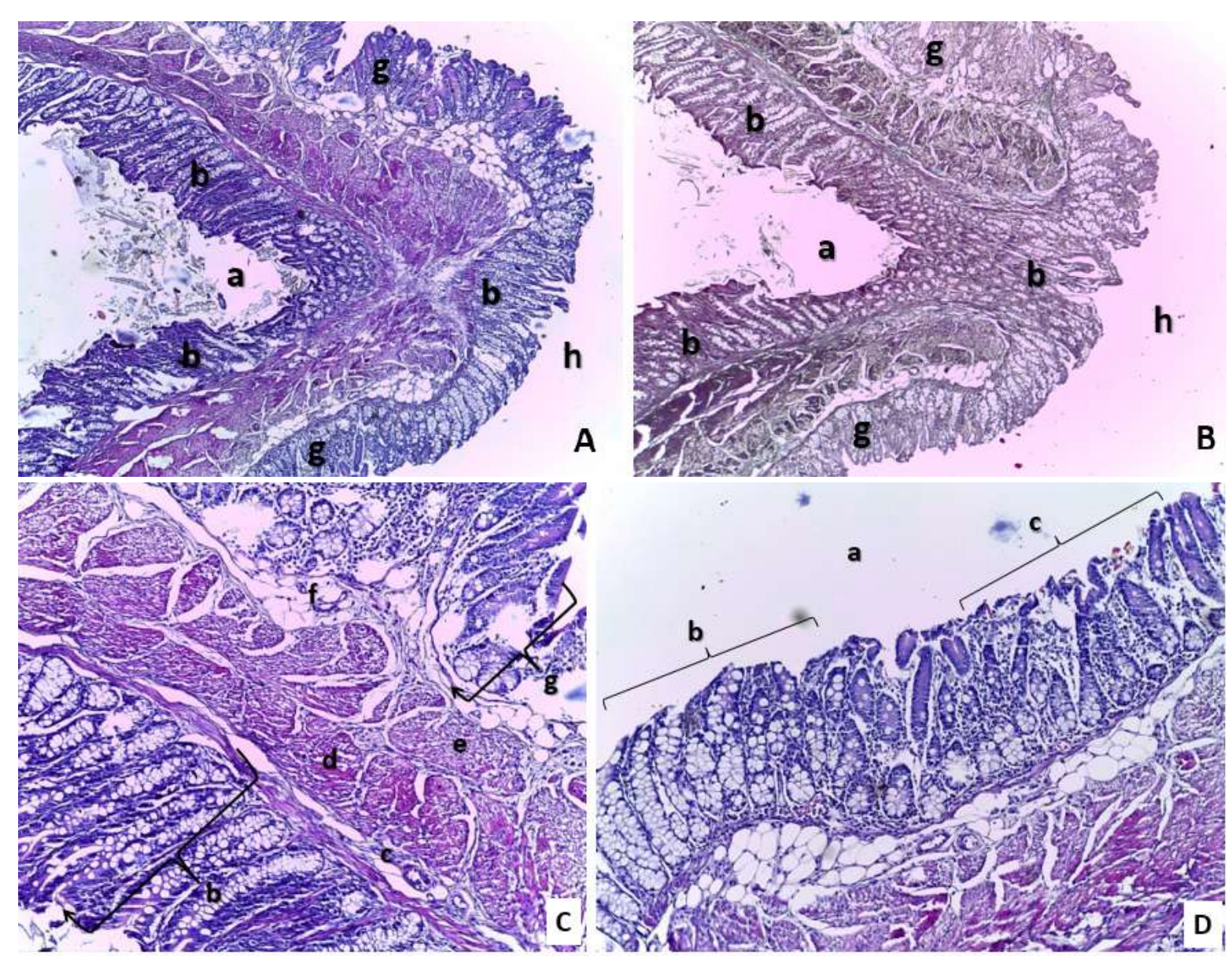

Las valvas cecocólicas presentaron una túnica mucosa con la misma estructura que la del ciego, recubriéndolas en toda su extensión (figura 10). La túnica submucosa presentó tejido conjuntivo laxo, escaso y discontinuo, con presencia de vasos sanguíneos en toda su extensión. Al corte histológico realizado, la túnica muscular se observó como una porción de tejido muscular liso presente en la base de la valva y parte de su recorrido, la cual presentó además plexos nerviosos mientéricos. La valva menor tuvo menor presencia de túnica muscular (figura 10).

La mucosa interna de la papila ileal presentó un epitelio cilíndrico simple con células caliciformes, formando vellosidades y a nivel de la base, criptas que contenían glándulas de Lieberkühn. La túnica muscular se observó compuesta de dos capas continuas de músculo liso, la circular interna del ciego y la circular interna del íleon formando el esfínter de

a. Luz del íleon, b. Túnica mucosa del íleon, c. Túnica submucosa del íleon, d. Túnica muscular circular interna del íleon, e. Túnica muscular circular interna del ciego, f. Túnica submucosa del ciego, g. Túnica mucosa del ciego, h. Luz del ciego. Figura 11. Papila ileal del ciego del cuy (Cavia porcellus) masculino de 8 semanas de edad Raza Perú. A: Tinción H-E (4x), B: Tinción tricrómico de Mallory (4x), C: Fusión de las capas musculares a nivel de la papila ileal, tinción H-E (40x). D: Cambio abrupto de la mucosa ileal a mucosa cecal a nivel de la papila ileal, tinción H-E (40x). 
la papila a nivel del orificio ileocecal (figura 11). Entre ambas capas se observaron plexos nerviosos mientéricos.

La mucosa del orificio ileocecal conservó las características propias del íleon, sin embargo, en la porción del borde externo de la papila, se observó la transición abrupta entre la mucosa del íleon y del ciego (figura 11). La pared externa de la papila se observó recubierta por la mucosa del ciego.

El pliegue ileocecal se observó compuesto por tejido adiposo y tejido conjuntivo laxo con presencia de fibroblastos, así como vasos sanguíneos de mediano calibre.

\section{DISCUSIÓN}

El estudio del ciego del cuy es comparable con otras especies como el equino (Equus caballus) y el conejo (Oryctolagus cuniculus), ya que en estos herbívoros dependen de la función fermentativa en ciego y colon para cubrir parte de sus requerimientos nutricionales (Cunningham, 2003).

El estudio confirmó que el cuy nace con todas sus estructuras del ciego presentes, en el lapso de horas o días completa su rotación, y posteriormente solo aumenta sus dimensiones, listas para entrar en funcionamiento. La explicación de por qué el tiempo de rotación del ciego del cuy es tan variable es algo que queda por dilucidar. Por tener una gestación larga, en promedio 67 días (Chauca, 1997), el cuy nace con el ciego a término. En cambio, en el conejo la gestación es de 30 días y las crías no nacen a término (Lebas, 1996) por lo cual el ciego no es funcional hasta completar su desarrollo aproximadamente al mes de edad (Leng, 2008).

En cuy y conejo (Suckow, 2012), el ciego ocupa gran parte de la cavidad abdominal, ventralmente se relaciona con el piso del abdomen y por el lado derecho se relaciona con las asas del intestino delgado y colon, en cambio, en el caballo, el ciego está situado a la derecha del plano medio y se relaciona al flanco (Getty, 2008). Estas relaciones anatómicas son evidenciadas en nuestro estudio.

La base del ciego en el cuy se encuentra en posición dorsal y al lado izquierdo de la cavidad abdominal, en contraste con el conejo y equino donde ubica en posición dorsal y al lado derecho de la cavidad abdominal (Horne, 1948; Getty, 2008). En las especies en discusión la base del ciego delimita del cuerpo por medio de una constricción medianamente marcada.
El cuerpo del ciego del cuy adopta la forma de una "V" con una marcada flexura orientada en caudal. Esta conformación se contrasta con lo reportado por Horne (1948) en el conejo donde el cuerpo del ciego adopta la forma de doble espiral, y con lo reportado por Getty (2008) en el equino donde el ciego adquiere la forma de una coma con la base en dorsal y el cuerpo en dirección ventro craneal.

El vértice del ciego delimita del cuerpo por medio de una marcada flexura craneal, el vértice es alargado, amplio, de función fermentativa y posición variada debido a la ausencia del pliegue cecocólico. Cuando se encuentra en dorsal mayormente se desplaza hacia el lado izquierdo, cuando se dirige en ventral lo hace hacia el lado derecho. A diferencia del conejo, el vértice del ciego del cuy no presenta apéndice vermiforme (Bustamante-Laverde, y Bustamante-Velasco, 2011).

Macroscópicamente las tenias se observan a manera de cintas delgadas, de color claro, que se extienden a lo largo del ciego dividiendo las saculaciones del cuy en tres filas; mientras que el equino, presenta cuatro (Getty, 2008).

En el cuy, la tenia dorsal se puede considerar como la principal del ciego por su ubicación y ser la más ancha de las tres. En cuanto a la tenia craneal en el cuy, Jhonson (2006) y Suckow (2012) la consideran como tenia media o medial por su posición intermedia entre las tenias dorsal y ventral. En el presente trabajo por su ubicación y trayecto se le denominó tenia craneal.

Las paredes del ciego están conformadas por filas de saculaciones las que permiten una mayor capacidad de recepción de contenido digestivo al órgano y el tránsito del alimento. En el cuy el número de saculaciones se mantiene entre las diez en cuyes recién nacidos y trece saculaciones en cuyes de ocho semanas de edad.

Las constricciones están representadas internamente por pliegues semilunares. En el cuy y equino los pliegues tienen un trayecto perimétrico entrecortado debido a la presencia de las tenias a diferencia del conejo donde los pliegues semilunares son continuos, de trayecto espiralado y reciben el nombre de "válvula espiral" (Horne, 1948).

Histológicamente, la túnica muscular es la que predomina a la observación, donde la capa circular interna determina el perímetro y espesor de la pared del ciego. En el cuy, la capa longitudinal externa 
solo está presente en las tenias (Gregerson, 1996), a diferencia del equino donde la longitudinal externa es continua, engrosándose a nivel de sus cuatro tenias (König, 2005)

En el examen comparativo entre el cuy y el equino ambos presentan la papila ileal en la base del ciego, el conejo carece de ella debido a la cercanía con el saco redondo. La presencia en el cuy de una verdadera papila ileal, indica la existencia de un mecanismo aún no estudiado de coordinación entre la llegada del contenido proveniente del ileón previa a la cecotrofia y su recorrido en el ciego y el trayecto del contenido ileal postcecotrofia. En el cuy, microscópicamente la papila ileal está tapizada por la mucosa del íleon, además al igual que el equino presenta una capa muscular lisa que forma el esfínter ileal (König, 2005). No se observó un plexo venoso mencionado por König (2005) en el equino.

El cuy presenta dos valvas mientras que el conejo posee una valva y un pliegue intermedio, esto podría indicar diferentes mecanismos de tránsito intestinal. En el conejo el colon podría actuar como un mecanismo selector en función de la composición de la ingesta selecciona si el alimento retorna al ciego (Quesenberry y Carpenter, 2012), y en el cuy sería a la inversa.

En el cuy al igual que en el caballo las placas de Peyer se observaron relacionadas a la curvatura mayor del ciego (Getty, 2008), presentándose en el cuy a manera de panal de abejas. Histológicamente, las placas de Peyer se observan como agregaciones de folículos linfoides (Di Fiore, 2001). En el cuy se encuentran en la túnica submucosa, en el conejo y equino pueden ubicarse en la mucosa o submucosa rompiendo la capa muscular de la mucosa (Malla, 2003).

Se reconocen en el cuy tres grupos de ganglios linfáticos relacionándose unos a la constricción entre base y cuerpo o en la constricción entre cuerpo y vértice. En el equino estos se asocian a las tenias medial y lateral (Getty, 2008; König, 2005), en el conejo se agregan a poca distancia de la unión dorsal del mesenterio (Horne, 1948).

El cuy presenta como medios de fijación los pliegues ileocecal, ileocecal accesorio y el pliegue cecocólico, estos le dan al órgano una forma particular en relación a lo observado por otros autores para el caso del equino y conejo (König, 2005; Horne, 1948).
Según Chauca (1997), la relación entre el peso vivo del cuy y el peso del ciego es de hasta $15 \%$. En el presente estudio, se encontró que a las diferentes edades la relación varió entre el 1\% para los animales recién nacidos y el $12 \%$ para los animales de cuatro semanas (tabla 5), en los animales de ocho semanas (edad de beneficio para el cuy parrillero) se encontró que la relación disminuía a $8 \%$, esto probablemente por el ayuno previo al beneficio.

\section{Correspondencia:}

Melissa Jara Espinoza

Correo electrónico: melissa.jara@upch.pe

\section{REFERENCIAS BIBLIOGRAFICAS}

1. American Veterinary Medical Association. (2013). AVMA Guidelines for the Euthanasia of Animals. Schaumburg, USA: AVMA.

2. Bustamante-Laverde, J., \& Bustamante-Velasco, J. (2011). Producción y Enfermedades de conejos. Lima, Perú: Universidad Nacional Mayor de San Marcos, Facultad de Veterinaria y Zootecnia,

3. Carpenter, J. (2001). Exotic animal formulary. Philadelphia: W.B.Saunders.

4. Church, D. (1993). El Rumiante: Fisiología digestiva y nutrición. Zaragoza, España: Editorial Acribia.

5. Chauca, L. (1997). Producción de cuyes (Cavia porcellus). Roma,Italia: FAO.

6. Cunningham, J. (2003). Fisiología Veterinaria. (Tercera Edición). Madrid: Editorial Elsevier.

7. Dellmann, H. (1993). Histología veterinaria. Zaragoza, España: Editorial Acribia.

8. Di Fiore, J. (2001). Histología de Di Fiore: Texto y Atlas. España: Editorial el Ateneo.

9. Esquerre, J., Valenzuela, A., \& Candela, E. (1974). Digestión microbiana en cuyes criollos de la altura. Rev Inv Pec (IVITA), 3(1), 67-76.

10. Getty, R. (2008). Anatomía de los animales domésticos. (Quinta Edición). Barcelona, España: Elsevier - Masson.

11. Gregerson, H. (1996). Essentials of experimental surgery: Gastroenterology. Amsterdam, The Netherlands: CRC Press.

12. Horne, E. (1948). Bensley's practical anatomy of the rabbit. Philapelphia, USA: The Blakiston Company.

13. Instituto Nacional de Innovación Agraria. (2018). INIA realiza investigación para uniformizar partos en cuyes a fin de incrementar su producción. Lima: Instituto Nacional de Innovación Agraria. Recuperado de: http://www.inia.gob.pe/2018-nota-151/

14. Jhonson, C. (2006). Anatomy and physiology of the rabbit and rodent gastrointestinal system. (9-17). Nashville: Exotic Mammal Veterinarians. 
15. König, H. (2005). Anatomía de los Animales Domésticos: Texto y atlas en color. Madrid: Editorial Médica Panamericana.

16. Lebas, F. (1996). El conejo: cría y patología. Roma, Italia: FAO.

17. Leng, R. (2008). Digestion in the Rabbit: a new look at the effects of their feeding and digestive strategies. Phnom Penh, Cambodia: Mekarn Workshop.

18. Malla, B. (2003). A Study in "Vermiform Appendix" a cecal appendage in common laboratory mammals. Kathmandu University Medical Journal, 1(4), 272275.

19. Newman, K. (2001). Crianza de cuyos. Nebraska, Estados Unidos: Serie Agronegocios Editorial Iberoamericana.

20. Padilla, F. (2006). Crianza de cuyes. Lima, Perú: Empresa Editora Macro.

21. Pariona, W. (2014). Salud y enfermedad en Ayacucho: La medicina tradicional en el escenario del siglo
XXI. (Tesis para optar el grado de Doctor en Ciencias Sociales, especialidad en Antropología, Universidad Nacional Mayor de San Marcos, Lima, Perú).

22. Quesenberry, K., \& Carpenter, J. (2012). Ferrets, rabbits and rodents. Clinical medicine and surgery. New York, USA: Saunders.

23. Suckow, M. (2012). The Laboratory Rabbit, Guinea Pig, Hamster, and Other Rodents. New York, USA: Elsevier.

24. Tineo, I. (2015). Evaluación de tres niveles de proteína en el engorde de cuyes mejorados en la EE, Canaán - INIA a 2750 m.s.n.m. Ayacucho. (Tesis para optar el título de Ingeniero Agrónomo, Universidad Nacional de San Cristobal de Huamanga, Ayacucho, Perú).

25. Valencia, R. (1992). Anatomía del pollo, cobayo y conejo. Lima, Perú: Universidad Nacional Mayor de San Marcos. 